\title{
Pulmonary Hypertension in Children with Congenital Left to Right Cardiac Shunt Anomalies
}

\author{
Chaity Barua $^{1^{*}}$ \\ Sunam Kumar Barua \\ Md Zahid Hossain ${ }^{1}$ \\ Tahmina Karim ${ }^{1}$
}

'Department of Paediatric Cardiology Bangabandhu Sheikh Mujib Medical University Dhaka, Bangladesh.

${ }^{2}$ Department of Physical Medicine \& Rehabilitation Dhaka Medical College, Dhaka, Bangladesh.

\section{*Correspondence to:}

\section{Dr. Chaity Barua}

Medical Officer

Department of Paediatric Cardiology

Bangabandhu Sheikh Mujib Medical University Dhaka, Bangladesh.

Mobile: +8801818411652

Email :sunam1971@hotmail.com

www.banglajol.info/index.php/CMOSHMCJ

\section{Abstract}

The Normal Pulmonary Artery (PA) systolic pressure of children and adults is $\leq 30$ $\mathrm{mm} \mathrm{Hg}$ and the mean PA pressure is $<25 \mathrm{~mm} \mathrm{Hg}$ at sea level. Pulmonary hypertension $(\mathrm{PH})$ is defined as a mean pulmonary artery pressure $>25 \mathrm{~mm} \mathrm{Hg}$ at rest or $>30 \mathrm{~mm} \mathrm{Hg}$ during exercise. An increase in pulmonary flow, vascular resistance, or both can result in pulmonary hypertension. Pulmonary Arterial Hypertension (PAH) commonly arises in patients with Congenital Heart Diseases (CHD) are usually associated with increased pulmonary blood flow. Greater number of patients with Pulmonary Arterial Hypertension (PAH), associated with congenital heart disease, are now surviving into adulthood, many with increasingly complex cardiac defects. Patients with cardiac defects which result in left-to-right shunting tend to develop PAH, owing to the increased shear stress and circumferential stretch induced by pulmonary blood flow, which leads to endothelial dysfunction and progressive vascular remodeling followed by vascular resistance. Pulmonary hypertension in association with congenital heart diseases is seen in large systemicto-pulmonary communications such as Ventricular Septal Defect (VSD), Patent Ductus Arteriosus (PDA) atrioventricular septal defects, aorticopulmonary window defect etc. Pulmonary hypertension associated with large L-R shunt lesions (e.g. VSD, PDA) is called Hyperkinetic Pulmonary Hypertension (PH). It is the result of an increase in pulmonary blood flow, a direct transmission of the systemic pressure to the pulmonary artery, and compensatory pulmonary vasoconstriction. Hyperkinetic $\mathrm{PH}$ is usually reversible if the cause is eliminated before permanent changes occur in the pulmonary arterioles. If large L-R shunt lesions are left untreated, irreversible changes take place in the pulmonary vascular bed, with severe pulmonary hypertension and cyanosis due to a reversal of the L-R shunt. This stage is called Eisenmenger syndrome or Pulmonary Vascular Obstructive Disease (PVOD). Surgical correction is not possible at this stage. Due to lack of formal study which of the L-R congenital shunt is more commonly associated with the development of pulmonary hypertension is not known the cross-sectional study therefore intends to find the pattern of congenital L-R heart diseases commonly attributed to the development pulmonary hypertension. The diagnosis of the abovementioned congenital heart disease will be made by echocardiography.

In this study, most of the participant [22 (44.0\%)] were in the ' $\leq 1$ years' age group, female were proportionately higher, most patients presented with cough and difficulty in breathing, dyspnoea and tachycardia were the most common clinical findings, murmur mostly systolic were found, Eisenmenger syndrome was not found in any child, ASD was the most common congenital anomaly. About four-fifth of the participants had single congenital anomaly. Two-fifth of the participant was found having severe PAH. Significant correlation were revealed between age group and Pulmonary arterial pressure $(\mathrm{R}=0.775)$, Status of $\mathrm{PAH}$ was found significantly different $(p<0.05)$ in age groups and presence of number of anomalies.

Key words: PAH (Pulmonary Arterial Hypertension); ASD (Arterial Septal Defect); VSD ( Ventricular Septal Defect); PDA (Patent Ductus Arteriosus). 


\section{INTRODUCTION}

Pulmonary Hypertension is defined as a mean pulmonary artery pressure $>25 \mathrm{~mm} \mathrm{Hg}$ at rest or $>30 \mathrm{~mm} \mathrm{Hg}$ during exercise ${ }^{1,2}$. It is one of the serious Complications of Congenital Heart Disease (CHD). After Idiopathic PAH (IPAH) and PAH associated with Connective Tissue Diseases (PAH-CTD), it is third most common form of $\mathrm{PAH}^{3}$. The incidence of congenital heart disease is approximately 8 per 1000 live births, and approximately $30 \%$ of children who do not undergo surgical repair will develop pulmonary vascular disease. Patients with $\mathrm{PAH}$ related to $\mathrm{CHD}$ who are not candidates for surgical correction are treated similar to IPAH patients. The natural history of such patients tends to be better than those with other types of $\mathrm{PAH}^{4}$.

Although traditionally most cases of PHD-CHD have arisen in children, the demographics are changing. The prevalence of congenital heart defect in adults and adolescents was reported to increase between 1985 and 2000, probably due to more paediatric patients surviving into adulthood. Furthermore, with the progress in paediatric cardiology and cardiac surgery, there is likely to be a reduction in the number of adult patient with simple CHD (Such as ventricular septal defects and parent ductus arteriosus), and an increase in those with complex CHD (Such as single-ventricle physiology) who may develop pulmonary vascular lesions after undergoing palliative procedures in early childhood ${ }^{5}$. Other complex congenital heart diseases associated with pulmonary arterial hypertension are complete atroventricular septal defect, truncus arteriosus, transposition of the great arteries with VSD (Without pulmonary stenosis) and/or patent ductus arteriosus etc ${ }^{6}$.

Clinical picture is variable depending upon the patient's age, underlying congenital heart disease, and the L-R shunting across the defect. In a young infant born with a large systemic to pulmonary communication, pulmonary hypertensions likely to be severe. These cases present with features such as tachypnea, tachycardia, feeding difficulties, failure to thrive and hepatomegaly. Cardiac examination reveals shunt murmur and flow murmurs. If not intervened and repaired, some of these children are lost due to severe respiratory tract infections and heart failure. In those surviving, pulmonary vascular disease develops at the end of first or second year, and pulmonary vascular resistance rises. The degree of shunting also decrease and heart failure improves. As the pulmonary vascular disease progresses, the shunt may become bidirectional or reverse leading to Eisenmenger syndrome. In Eisenmenger syndrome dyspnea or breathlessness or exertion is the most common symptom. Others include chest pain, syncope or presyncope and hemoptysis. In physical examination cyanosis and clubbing may be seen, differential cyanosis is present in $50 \%$ case of PDA. Giant ' $a$ ' wave venous pulse is uncommon. The right ventricular heave is present, pulmonary component of second heart sound is loud. Absence of the shunt and flow murmurs. Later when heart failure sets in, murmur of tricuspid regurgitation may be audible. A pulmonary click is heard in two-third of cases. An early diastolic murmur of pulmonary regurgitation $50-60 \%$ of cases $^{7}$. Jugular venous distension, liver enlargement, peripheral edema, ascites and cold extremities characterize patients in right heart failure ${ }^{8}$.
Cardiac defects resulting in left-to-right shunting cause PAH because the increased pulmonary blood flow induces increases in shear stress and circumferential stretch. Once the increasing, pulmonary vascular résistance equals systemic resistance, the left-to-right shunts becomes bi-directional, and once pulmonary vascular resistance exceeds systemic resistance, shunt reversal and the development of Eisenmenger syndrome occurs ${ }^{5}$.

Several types of congenital heart diseases are observed to be associated pulmonary hypertension. The present study is intended to see the types of congenital heart diseases with leftto-right shunt that are commonly associated pulmonary hypertension and the status of hypertension as well.

\section{OBJECTIVES}

General:

Evaluate the status of pulmonary hypertension in children with congenital heart disease having left to right shunt.

Specific:

1. Observe the association of pulmonary hypertension with age of the study children.

2. Assess the mode of clinical presentation of those children.

3. Assess the types of left to right congenital cardiac shunt diseases commonly lead to pulmonary hypertension.

\section{MATERIALS \& METHODS}

Study design

This was a cross-sectional type of study.

Place of study

The study was conducted at the Department of Paediatric Cardiology, Bangabandhu Sheikh Mujib Medical University (BSMMU) Dhaka.

\section{Period of study}

The study was conducted over a period of 6 (six) months from June 2012 to December 2012.

Subjects of the study

All the Children of congenital heart diseases with or without pulmonary arterial hypertension with left-to-right shunt were the study population.

\section{Sample size}

50 cases were recorded.

\section{Sampling method}

The subjects meeting the predefined eligibility criteria were selected purposively from the study population.

\section{Inclusion criteria}

The children with congenital left to right cardiac shunt anomalies.

\section{Exclusion criteria}

1) Very sick children.

2) Parents of children refusing to give written consent. 


\section{Data collection}

\section{Procedure of preparing and organizing materials}

Data were collected using a structured questionnaire (Research Instrument) containing all the variables of interest. The questionnaire was finalized following pretesting. Collected data were checked daily and edited (If needed).

\section{Data collection instruments}

A semi-structured data sheet was designed and used as data collection instrument.

\section{Equipments to be used}

All the congenital cardiac shunt anomalies which were suppose to increase the blood flow to lung (VSD, ASD, PDA, AV canal defect, AP window, Truncus arterious, TGA with left to right shunt, SV anomaly with increased pulmonary blood flow, PA with major collaterals to lung etc.) were diagnosed with the help of echocardiography. The pulmonary hypertension was also detected using echocardiography.

\section{Procedure of data collection}

Data will be collected from the selected children as well as from their parents by interview, physical examination, and from echocardiography using a structured questionnaire.

\section{Procedure of data analysis}

Data were processed and analysed using computer software SPSS (Statistical Package for Social Sciences). The test statistics to be used were descriptive statistics, Student's t-Test and Chi-square $\left(\chi^{2}\right)$ Test. Level of significance was set at 0.05 $(5 \%)$ and $\mathrm{p}<0.05$ was considered significant.

\section{Quality Controls}

It was extremely important that data collection was of good quality. To ensure it, the collected data were checked daily and missing or incorrect data were corrected if needed.

\section{Ethical Measures}

Keeping compliance with Helsinki Declaration for Medical Research Involving Human Subjects 1964, the parents of the selected subjects were informed verbally about the study design, the purpose of the study and their right to withdraw their children from the project at any time, for any reason, what-so-ever. The parents of study subjects who had given informed consent to allow their children to participate in the study were included as study sample.

\section{RESULTS}

Table 1 : Distribution of the children by their age $(n=50)$

\begin{tabular}{lcc} 
Age & Frequency & (Percent) \\
<1 years & 22 & 44.0 \\
1-5 years & 19 & 38.0 \\
$>5$ years & 9 & 18.0 \\
\hline
\end{tabular}

Mean $\pm \mathrm{SD}=3.1912 \pm 3.94387$, range $=25$ days -14 years

Table 1 shows that, most of the participant [22 (44.0\%)] were in the ' $<1$ years' age group, Mean $\pm \mathrm{SD}$ of age was calculated to be, (3.1912 \pm 3.94387$)$ and age ranged from 25 days to 14 years.

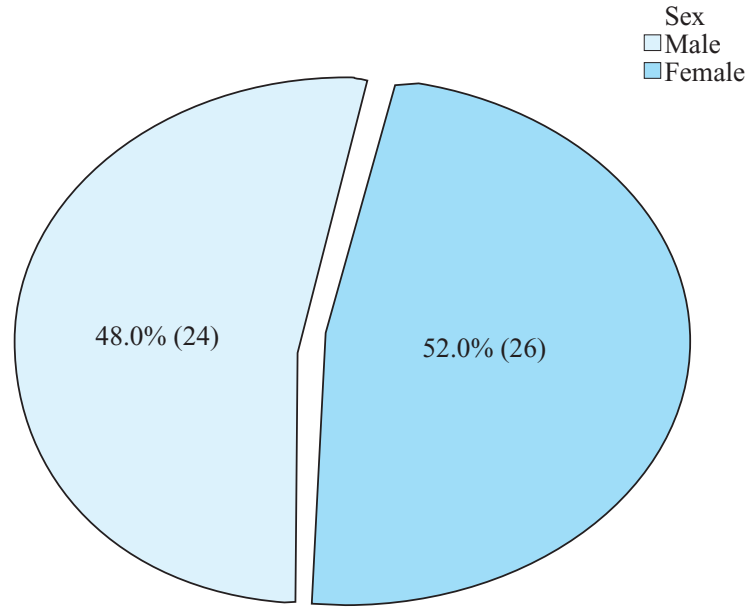

Figure 1 : Distribution of the participants by their gender $(n=50)$

Figure 1 illustrates that, about half of the participants [24 (48.0\%)] were Males. Male: Female ratio was about 1:1.08 and female were proportionately higher in count.

Table 2 : Distribution of the children by their presenting complaints $(\mathrm{n}=50)$

\begin{tabular}{lcc} 
Symptoms & Frequency & Percent \\
Difficulty in breathing & 32 & 64.0 \\
Feeding difficulties & 25 & 50.0 \\
Cough & 41 & 82.0 \\
Poor weight gain & 22 & 44.0 \\
Chest pain & 3 & 6.0 \\
Syncope & 2 & 4.0 \\
\hline
\end{tabular}

Table 2 shows that, patients presented with multiple complaints; cough $[41(82.0 \%)]$ and difficulty in breathing [32 $(64.0 \%)]$ was the most mentioned symptoms at presentation. Half of the patients came with feeding difficulties [25 (50.0\%)] along with poor weight gain [22 (44.0\%)]. Only $3(6.0 \%)$ had chest pain and $2(4.0 \%)$ experienced syncope.

Table 3 : Distribution of the children by the signs found on examination $(n=50)$

$\begin{array}{lrr}\text { Signs } & \text { Frequency } & \text { Percent } \\ \text { Dyspnoea } & 27 & 54 . .0 \\ \text { Cyanosis } & 2 & 4.0 \\ \text { Clubbing } & 1 & 2.0 \\ \text { Peripheral oedema } & 0 & 0.0 \\ \text { Hepatomegaly } & 5 & 10.0 \\ \text { Anaemia } & 30 & 60.0 \\ \text { Pulse (Tachycardia) } & 30 & 60.0 \\ \text { Blood pressure (Normal) } & 42 & 84.0 \\ \text { ๙ N Normal }^{N} \text { Decreased } & 47 & 94.0 \\ & 3 & 6.0\end{array}$


Multiple signs were found in patients with congenital left to right cardiac shunt anomalies. According to Table 3, three-fifth of the patients [30 $(60.0 \%)]$ were found with tachycardia and anaemia. Again more than half of them [27 (54.0\%)] were suffering from Dyspnoea. Sings of prolonged suffering was found in older children, i.e. cyanosis [2 (4.0\%)] and clubbing [1 (2.0\%)].

Table 4 : Distribution of the children by their cardiac signs $(n=50)$

\begin{tabular}{|c|c|c|}
\hline Cardiac findings & Frequency & Percent \\
\hline Apex beat shifted & 6 & 12.0 \\
\hline Right ventricular heave & 21 & 42.0 \\
\hline Palpable $\mathrm{P}_{2}$ & 18 & 36.0 \\
\hline Loud pulmonary ejection click & 8 & 16.0 \\
\hline$\cong$ Systolic & 41 & 82.0 \\
\hline Diastolic & 0 & 0.0 \\
\hline$\sum$ Continuous & 9 & 18.0 \\
\hline
\end{tabular}

Table 4 illustrates that, murmurs were found in every child, out of those most [41 (82.0\%)] were systolic murmurs and rest were continuous murmurs [9 (18.0\%)], diastolic murmurs was not found. Other cardiac findings were Right ventricular heave in $21(42.0 \%)$, Palpable $\mathrm{P}_{2}$ in $18(36.0 \%)$, Loud pulmonary ejection click in $8(16.0 \%)$ and Apex beat shifted in $6(12.0 \%)$ of the children suffering from congenital left to right cardiac shunt anomalies.

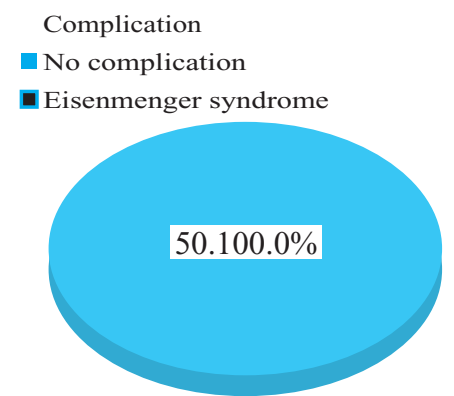

Figure 2 : Distribution of the participants by the complication of cardiac anomaly

Figure 2 shows that, fortunately there was no complication. That is Eisenmenger syndrome was not found.

Table 5 : Distribution of the children by their congenital cardiac anomalies $(\mathrm{n}=50)$

$\begin{array}{lcc}\text { Defect } & \text { Frequency } & \text { Percent } \\ \text { ASD } & 28 & 56.0 \\ \text { VSD } & 18 & 36.0 \\ \text { PDA } & 14 & 28.0 \\ \text { A-V Canal Defect } & 1 & 2.0 \\ \text { A-P Window } & 0 & 0.0 \\ \text { Single Ventricle } & 1 & 2.0 \\ \text { Truncus arteriosus } & 0 & 0.0 \\ \text { TGA } & 0 & 0.0 \\ \text { Pulmonary artery with collaterals } & 0 & 0.0\end{array}$

Table 5 explains that, on echocardiographic findings atrial septal defect (ASD) [28 (56.0\%)], ventricular septal defect (VSD) [18 (36.0\%)] and persistent ductus arteriosus (PDA) [14 $(28.0 \%)]$ were the most notable congenital anomalies. One case $(2.0 \%)$ of 'A-V canal defect' and 'single ventricle' was found in two individuals.

Table 6 : Distribution of the children by the presence of multiple defects $(n=50)$

$\begin{array}{lcc}\text { Multiple Defects } & \text { Frequency } & \text { Percent } \\ \text { Single defect } & 39 & 78.0 \\ \text { ASD + PDA } & 4 & 8.0 \\ \text { ASD + VSD } & 3 & 3.0 \\ \text { ASD + VSD + A-V Canal Defect } & 1 & 2.0 \\ \text { VSD + PDA } & 2 & 4.0 \\ \text { VSD + Single Ventricle } & 1 & 2.0\end{array}$

Evidenced from Table 6, about four-fifth [39 (78.0\%)] of the participants had single congenital anomaly. Out of the remaining $11(22.0 \%)$ children ASD e PDA was 4 (8.0\%), ASD $\overline{\mathrm{e}}$ VSD was $3(6.0 \%)$, VSD $\overline{\mathrm{e}}$ PDA was $2(4.0 \%)$ and a single case $(2.0 \%)$ for ASD e VSD e A-V Canal Defect and VSD $\bar{e}$ Single Ventricle.

Table 7 : Distribution of the children by their Status of PAH $(n=50)$

$\begin{array}{lcr}\text { PAH } & \text { Frequency } & \text { (Percent) } \\ \text { Normal } & 9 & 18.0 \\ \text { Mild } & 9 & 18.0 \\ \text { Moderate } & 13 & 26.0 \\ \text { Severe } & 19 & 38.0\end{array}$

Mean $\pm \mathrm{SD}=57.992 \pm 30.7658$, range $=20-130 \mathrm{~mm}$ of $\mathrm{Hg}$

Table 7 shows that, about two-fifth of the participant [19 $(38.0 \%)$ ] had been suffering from severe pulmonary arterial hypertension, more than a quarter $[13(26.0 \%)]$ had moderate $\mathrm{PAH}$ and mild $\mathrm{PAH}$ was found in $9(18.0 \%)$ individual. However, about one-fifth [9 (18.0\%)] had normal pulmonary arterial pressure. Mean \pm SD of pulmonary arterial pressure was $57.992 \pm 30.7658$ with a range of $20-130 \mathrm{~mm}$ of $\mathrm{Hg}$.

Figure 3 : Distribution of the participants by their age and pulmonary arterial pressure (Scatter diagram)

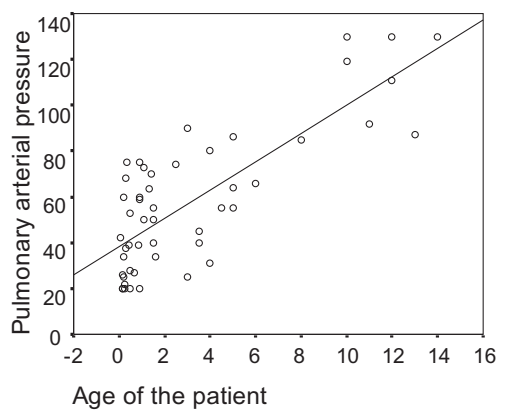


Pearson Correlation $=0.775$, Sig. $(2$-tailed $)=0.0001$.

** Correlation is significant at the 0.01 level (2-tailed).

Linear regression model: $\mathrm{R}=0.775$, Sig. $=0.0001$.

Figure 3 explains that, with the advancement of age pulmonary arterial pressure increases. Calculation indicated that there was statistically significant correlation between age and pulmonary arterial pressure (Pearson Correlation $=0.775$ and Linear regression model, $\mathrm{R}=0.775$ ).

Table 8 : Distribution of the children by their age group and status of PAH $(n=50)$

\begin{tabular}{lccccc}
\multicolumn{7}{c}{ Status of PAH } & & \\
age of the & Normal & $\begin{array}{c}\text { Mild } \\
\text { participant }\end{array}$ & Moderate & $\begin{array}{c}\text { Severe } \\
\text { (Percent) }\end{array}$ & Total \\
(Percent) & (Percent) & (Percent) & \\
1 years & 16.0 & 12.0 & 10.0 & 6.0 & 44.0 \\
1-5 years & 2.0 & 6.0 & 14.0 & 16.0 & 38.0 \\
$>$ 5 years & 0.0 & 0.0 & 2.0 & 16.0 & 18.0 \\
Total & 18.0 & 18.0 & 26.0 & 38.0 & 100.0 \\
\hline
\end{tabular}

$\chi^{2}=21.548 ; \mathrm{df}=6 ; \mathrm{p}$-value $=0.001$

All the children above 5 years of age [9 (18.0\%)] had moderate to severe PAH. Table 8 illustrates that, most of the patients [ 8 $(16.0 \%)$ out of $9(18.0 \%)]$ with normal PAH was from children $\leq 1$ years age groups. Chi-square calculated that, there was statistically significant difference in age group and status of PAH $\left(\chi^{2}=21.548 ; \mathrm{df}=6\right.$; $\mathrm{p}$-value $\left.=0.001\right)$.

Table 9 : Distribution of the children by their age group and status of PAH $(n=50)$

\begin{tabular}{llllll}
$\begin{array}{l}\text { Number of } \\
\text { anomalies }\end{array}$ & $\begin{array}{c}\text { Sormal } \\
\text { (Percent) }\end{array}$ & (Percent) & $\begin{array}{l}\text { ModerateSevere } \\
\text { (Percent) }\end{array}$ & (Percent) \\
\hline Single & 18.0 & 18.0 & 20.0 & 22.0 & 78.0 \\
Multiple & 0.0 & 0.0 & 6.0 & 16.0 & 22.0 \\
Total & 18.0 & 18.0 & 26.0 & 38.0 & 100.0 \\
\hline$\chi^{2}=9.561 ; \mathrm{df}=3 ; \mathrm{p}$-value $=0.023$ & & &
\end{tabular}

Table 9 chalks out that, all the children [11 (22.0\%)] with multiple congenital anomalies had moderate to severe PAH. There was statistically significant difference in presence of number of anomalies and status of PAH $\left(\chi^{2}=9.561\right.$, df $=3$, $\mathrm{p}$-value $=0.023$.

\section{DISCUSSION}

This study was undertaken with the objective to evaluate the status of pulmonary hypertension in children with congenital heart disease having left to right shunt. A total of 50 children were included in this study.
Most of the participant [22 (44.0\%)] were in the ' $\leq 1$ years' age group; Mean \pm SD of age was calculated to be, (3.1912 \pm $3.94387)$ and age ranged from 25 days to 14 years. About half of the participants [24 (48.0\%)] were Males. Male: Female ratio was about 1:1.08 and female were proportionately higher in count. Similarly Reddy SM, Thingnam SKS and Joshi K included twenty patients in their study, 11 were males and 9 females. The age ranged from 4 months to 25 years (mean age5.8 years $)^{9}$. on the other hand Yau KI, Fang LJ and $\mathrm{Wu} \mathrm{MH}$ enrolled twenty-six infants (13 males, 13 females) with CHD and left-to-right shunt from lower age group [9 days to 11 months (median, 3.3 months) $]^{10}$. Sharmin LS, Haque MA, Bari MI, Ali MA conducted a study consisiting 115 patients suffering from CHD, age ranging from newborn to 12 years. Male and female ratio was 1.3:1. Males were predominant in VSD, TOF, A-V canal defect and single ventricle with single A$\mathrm{V}$ canal defect. Females were predominant in ASD, PDA, COA, TGA and multiple lesion but equal distribution in $\mathrm{PS}^{11}$.

Patients presented with multiple complaints; cough [41 $(82.0 \%)]$ and difficulty in breathing [32 (64.0\%)] was the most mentioned symptoms at presentation. Half of the patients came with feeding difficulties [25 (50.0\%)] along with poor weight gain $[22(44.0 \%)]$. Only $3(6.0 \%)$ had chest pain and $2(4.0 \%)$ experienced syncope. Multiple signs were found in patients with congenital left to right cardiac shunt anomalies. Three-fifth of the patients [30 (60.0\%)] were found with tachycardia and anaemia. Again more than half of them [27 (54.0\%)] were suffering from Dyspnoea. Sings of prolonged suffering was found in older children, i.e. cyanosis $[2(4.0 \%)]$ and clubbing [1 (2.0\%)]. Murmurs were found in every child, out of those most $[41(82.0 \%)]$ were systolic murmurs and rest were continuous murmurs [9 (18.0\%)], diastolic murmurs was not found. Other cardiac findings were Right ventricular heave in 21 (42.0\%), Palpable $\mathrm{P}_{2}$ in 18 (36.0\%), Loud pulmonary ejection click in $8(16.0 \%)$ and Apex beat shifted in $6(12.0 \%)$ of the children suffering from congenital left to right cardiac shunt anomalies. Fortunately there was no complication. That is Eisenmenger syndrome was not found. Reddy SM, Thingnam SKS and Joshi K reported that, dyspnoea and recurrent chest infection were the commonest symptoms, seen in $60 \%$ of the cases studied. Orthopnoea and/or paroxysmal nocturnal dyspnoea suggestive of left heart failure were seen in 2 patients of ventricular septal defect and 1 patient with patent ductus arteriosus. Differential cyanosis/clubbing, evidence of longstanding pulmonary hypertension with reversal of shunt was not seen in any patient. A loud second heart sound due to accentuation of pulmonary component, a presumptive evidence of pulmonary arterial hypertension was found in 3 patients $(15 \%)^{9}$. In Bangladesh major clinical presentations of patients with CHD were breathlessness (60\%), fatigue (54.8\%), cough $(43.5 \%)$, poor weight gain $(41.7 \%)$, recurrent chest infection (34.8\%), feeding problem $(26.1 \%)$, cyanosis $(20 \%)$, clubbing 
(17.4\%), oedema $(10.4 \%)$, anaemia $(18.3 \%)$, polycythemia $(19.1 \%)$, tachycardia $(37.4 \%)$ and fast breathing $(43.5 \%)$. Murmur with or without thrill and cardiomegaly were the most important cardiac finding. Frequently observed complications were heart failure (18.3\%), pulmonary hypertension (13\%) and growth failure $(41.7 \%)^{11}$.

On echocardiographic findings Atrial Septal Defect (ASD) [28 (56.0\%)], Ventricular Septal Defect (VSD) [18 (36.0\%)] and Persistent Ductus Arteriosus (PDA) [14 (28.0\%)] were the most notable congenital anomalies. One case $(2.0 \%)$ of 'A-V canal defect' and 'single ventricle' was found in two individuals. About four-fifth [39 (78.0\%)] of the participants had single congenital anomaly. Out of the remaining $11(22.0 \%)$ children ASD e PDA was 4 (8.0\%), ASD e VSD was $3(6.0 \%)$, VSD $\bar{e}$ PDA was $2(4.0 \%)$ and a single case $(2.0 \%)$ for ASD $\overline{\mathrm{e}} \mathrm{VSD} \overline{\mathrm{e}}$ A-V Canal Defect and VSD e Single Ventricle. In Taiwan, the disease spectrum among the 26 cases included Ventricular Septal Defect (VSD: 12 cases), patent ductus atrocious (PDA: 4 cases), Atrial Septa1 Defect (ASD: 3 cases), VSD Plus PDA (2 cases), VSD Plus ASD 12 cases), VSD Plus ASD and PDA (1 case), VSD Plus mild Aortic Stenosis (AS) and Aortic Regurgitation (AR: 1 case), and coarctation of the aorta Plus PDA $(1 \text { case })^{10}$. In India on echocardiography, 13 patients had patent ductus arteriosus of 3 to $7 \mathrm{~mm}$ size (mean-5.35 \pm 1.39 $\mathrm{mm}$ ). Four patients had ventricular septal defect of 7-14 mm size (mean-9.75 mm). Two patients had atrial septal defect. One had Ostium primum type with $21 \mathrm{~mm}$ size. The other had Ostium secundum type with $34 \mathrm{~mm}$ size. One patient had mixed lesion with ventricular septal defect of $6 \mathrm{~mm}$ size and patent ductus arteriosus of $7 \mathrm{~mm}$ size $^{9}$. In Rajshahi Medical College Hospital, commonest congenital heart disease was VSD (42.6\%) followed by TOF (18.3\%), $\operatorname{ASD}(14.8 \%), \operatorname{PDA}(7.8 \%)$ and others $(15.5 \%)$.

About two-fifth of the participant [19 (38.0\%)] had been suffering from severe pulmonary arterial hypertension, more than a quarter $[13(26.0 \%)]$ had moderate PAH and mild PAH was found in $9(18.0 \%)$ individual. However, about one-fifth [9 $(18.0 \%)]$ had normal pulmonary arterial pressure.
Mean \pm SD of pulmonary arterial pressure was $57.992 \pm$ 30.7658 with a range of $20-130 \mathrm{~mm}$ of $\mathrm{Hg}$. Similarly Reddy SM, Thingnam SKS and Joshi $\mathrm{K}$ found that, peak systolic gradient of 20-120 mm Hg (mean-62.4 $\pm 23.74 \mathrm{~mm} \mathrm{Hg}$ ) and end diastolic gradient of 3-53 mm Hg (mean-25.13 $\pm 6.45 \mathrm{~mm} \mathrm{Hg}$ ). As young infants were enrolled by Yau KI, Fang LJ and Wu $\mathrm{MH}$, only ten cases had pulmonary artery hypertension detected by echocardiography ${ }^{10}$.

With the advancement of age, pulmonary arterial pressure increased. Calculation indicated that there was statistically significant correlation between age and pulmonary arterial pressure $($ Pearson Correlation $=0.775$, Sig. $(2$-tailed $)=0.0001$ and Linear regression model, $\mathrm{R}=0.775$, Sig. $=0.0001)$. All the children above 5 years of age [9 $(18.0 \%)]$ had moderate to severe PAH. most of the patients [8 (16.0\%) out of $9(18.0 \%)$ ] with normal PAH was from children $<1$ years age groups. Chisquare calculated that, there was statistically significant difference in age group and status of PAH $\left(\chi^{2}=21.548, \mathrm{df}=6\right.$, $\mathrm{p}$-value $=0.001)$. All the children $[11(22.0 \%)]$ with multiple congenital anomalies had moderate to severe PAH. There was statistically significant difference in presence of number of anomalies and status of PAH $\left(\chi^{2}=9.561, \mathrm{df}=3, \mathrm{p}\right.$-value $=$ $0.023)$.

\section{CONCLUSION}

Pulmonary arterial pressure gradually increases in patients with congenital left to right cardiac shunt anomalies with the advancement of their age. Status of PAH was higher in children with multiple congenital anomalies than those with single defect.

\section{DISCLOSURE}

All the authors declared no competing interest. 


\section{REFERENCES}

1. Erika B. Rosenzweig, Robyn J. Barst. Clinical Management of Patients with Pulmonary Hypertension. In: Allen, Hugh D., Driscoll, David J., Shaddy, Robat E, "et al". Moss and Adam's Heart Disease in Infants, children, and Adolescent: Including the fetus and young adult, Williams \& Wilkins. 2008;7:1356-1369.

2. Amy Hawkins, Robert Tulloh. Treatment of Pediatric Pulmonary Hypertension. Vascular Health and Risk Management. 2009;5: 509-524.

3. B. J. M. Mulder. Changing demographics of pulmonary arterial hypertension in congenital heart disease. Eur Respir Rev. 2010;19(118):308-313.

4. Stephen L. A., David B. B., Robyn J. B., Harrison W. F., Jonathan R. L, Michael A. M, "et al". ACCF/AHA Expert Consensus Document on Pulmonary Hypertension. A report of the American College of Cardiology Foundation Task Force on Expert Consensus Documents and the American Heart Association. 2009.

5. Gatzoulis MA, Alonoso-Gonzalez R, Beghetti M. Pulmonary arterial hypertension in pediatric and adult patients with congenital heart disease. Eur Resp Rev. 2009; 113:154-161.

6. Galie N, Hoeper MM, Humbert M Torbicki et al., Guidelines for the Diagnosis and Treatment of Pulmonary Hypertension: The Task Force for the Diagnosis of Pulmonary Hypertension of the European Society of Cardiology (ESC) and the European Respiratory Society (ERS), endorsed by International Society of Heart and Lung Transplantation (ISHLT). Eur Heart J. 2009; 30:2493-2537.

7. Anita Saxena., Pulmonary hypertension in congenital heart disease. Pulmonary Vascular Disease in the Developing World. 2009; 1(2):101-108.

8. Arif E, Remiadevi K.S, Kothari S S, Kumar R K, Nejatizadeh A, Puri G D, etal. Pulmonary Hypertension. ECAB Clinical Update: Cardiology.2008;1(6).

9. Reddy SM, Thingnam SKS, Joshi K. Study of Pulmonary Arterial Pressures and Histopathological Changes in Patients Having Congenital Heart Defects with Left-to-Right Shunt. Indian J Surg. 2011; 73(2):116-121.

10. Yau KI, Fang LJ, Wu MH. Lung Mechanics in Infants With Left-to-Right Shunt Congenital Heart Disease. Pediatric Pulmonology. 1996; $21: 42-47$.

11. Sharmin LS, Haque MA, Bari MI, Ali MA. Pattern and Clinical Profile of Congenital Heart Disease in A Teaching Hospital. The Journal of Teachers Association RMC, Rajshahi. 2008; 21 (2). 